\title{
Mid-term effect of balloon aortic valvuloplasty on mitral regurgitation in aortic stenosis
}

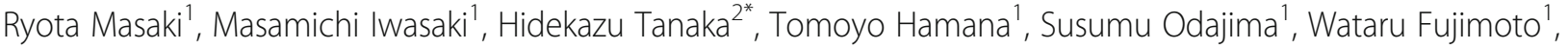 \\ Koji Kuroda', Yutaka Hatani ${ }^{1}$, Takumi Inoue ${ }^{1}$, Hiroshi Okamoto ${ }^{1}$, Masanori Okuda ${ }^{1}$, Takatoshi Hayashi ${ }^{1}$ and \\ Ken-ichi Hirata ${ }^{2}$
}

\begin{abstract}
Background: Balloon aortic valvuloplasty (BAV) offers an alternative to conventional aortic valve replacement in elderly and frail patients with severe aortic stenosis (AS) for whom there are no other effective options. We aimed to investigate the mid-term effect of BAV on mitral regurgitation (MR) in patients with severe AS.

Methods: Our analysis was based on the data from 83 patients with severe AS (mean age, $86 \pm 5$ years; female, 68) treated using BAV. Echocardiography was performed before the procedure and at 1 and 3 months after. MR was quantified by measuring the MR jet area, with more-than-moderate MR being clinically significant.

Results: Forty patients were classified in this group (MR group). Significant reduction of MR was observed in the MR group at 1 month and 3 months after procedure, with no improvement in patients in the non-MR group. At 3 months, 15 of the 40 patients in the MR group still had significant MR, with the change at 1 month in the left ventricular end-systolic dimension (OR: 1.36; 95\% Cl: 1.05-1.76; $P=0.022)$ and MR jet area (OR: 1.95; 95\% Cl: $1.16-$ 3.29; $P=0.012$ ) being predictive of persisting significant MR at 3 months after BAV. The prevalence of New York Heart Association functional class III or IV decreased at 1 and 3 months after BAV in both groups.
\end{abstract}

Conclusions: BAV provides a useful therapeutic strategy for elderly patients with severe AS who are not candidates for surgical or transcatheter aortic valve replacement, especially in those with significant MR.

Keywords: Balloon aortic valvuloplasty, Mitral regurgitation, Aortic stenosis

\section{Background}

The incidence of aortic stenosis (AS) is increasing as a result of aging of the general population, with poor survival anticipated without aortic valve replacement once symptoms develop $[1,2]$. Balloon aortic valvuloplasty (BAV) is offered as an alternative to conventional surgical aortic valve replacement (SAVR) or transcatheter

\footnotetext{
* Correspondence: tanakah@med.kobe-u.ac.jp

${ }^{2}$ Division of Cardiovascular Medicine, Department of Internal Medicine, Kobe University Graduate School of Medicine, 7-5-2, Kusunoki-cho, Chuo-ku, Kobe 650-0017, Japan

Full list of author information is available at the end of the article
}

aortic valve replacement (TAVR) for elderly and frail patients with severe AS, for whom there are no other effective options [3]. The current American College of Cardiology/American Heart Association guidelines state that BAV may be considered as a bridge-to-SAVR or -TAVR in patients with severe symptomatic AS (Class IIb, Level of Evidence C) [4]. Despite the current TAVR era, BAV can still be considered as a worthwhile treatment for severe AS, providing an urgent salvage option for patients with severe AS who are in cardiogenic shock and those who are not candidates for SAVR or TAVR, as well as providing a bridge-to-SAVR or -TAVR in

(c) The Author(s). 2020 Open Access This article is licensed under a Creative Commons Attribution 4.0 International License, which permits use, sharing, adaptation, distribution and reproduction in any medium or format, as long as you give appropriate credit to the original author(s) and the source, provide a link to the Creative Commons licence, and indicate if changes were made. The images or other third party material in this article are included in the article's Creative Commons licence, unless indicated otherwise in a credit line to the material. If material is not included in the article's Creative Commons licence and your intended use is not permitted by statutory regulation or exceeds the permitted use, you will need to obtain permission directly from the copyright holder. To view a copy of this licence, visit http://creativecommons.org/licenses/by/4.0/ The Creative Commons Public Domain Dedication waiver (http://creativecommons.org/publicdomain/zero/1.0/) applies to the data made available in this article, unless otherwise stated in a credit line to the data. 
patients in whom the benefit of valve replacement is uncertain and those with a temporary contraindication to valve replacement. Mitral regurgitation (MR) is commonly observed in patients with severe AS [5]. The resolution of AS, by means of SAVR or TAVR, leads to an immediate drop in left ventricular (LV) systolic pressure, which reduces the pressure gradient across the mitral valve and, thus, improves MR severity. On the other hand, the risk for mortality increases in patients with severe AS in whom MR fails to improve after SAVR or TAVR [6-8]. However, changes in MR after BAV and identification of patients with severe AS for whom BAV could be of benefit to decrease MR remain to be clarified. Accordingly, the aim of our study was to investigate the mid-term effect of BAV on MR in patients with severe AS.

\section{Methods}

\section{Study population}

We retrospectively studied 140 consecutive patients with severe AS who underwent BAV at Awaji Medical Center, between April 2014 and February 2018. BAV was indicated as a bridge-to-SAVR or -TAVR, as a treatment option for patients in whom SAVR or TAVR was not suitable due to severe comorbidity, for risk reduction by avoiding cardiac surgery, and for diagnostic purposes, to determine the implications of AS on patient's symptoms. Our study was approved by the ethics committee of Awaji Medical Center (No. 30-59), and the need for patient consent was waived due to the retrospective design of the study.

\section{Echocardiography examination}

Echocardiography was performed using commercially available ultrasound systems, namely the Aplio XG and Aplio Artida (Canon Medical Systems, Tochigi, Japan) and EPIQ7 (Philips Medical Systems, Andover, MA) systems. Echocardiography was performed before BAV, and at 1 and 3 months after BAV, with standard measurements obtained in accordance with the current guidelines of the American Society of Echocardiography/ European Association of Cardiovascular Imaging [9]. For the assessment of AS, the maximal aortic jet velocity was recorded using multiple echo windows, with the window providing the highest velocity signal selected. The maximal and mean pressure gradients across the aortic valve were calculated using a modified Bernoulli equation, with the aortic valve area estimated using the continuity equation and normalized to the body surface area (AVAi). AS was defined based on the recommendations of the American Heart Association and American College of Cardiology, with severe AS defined in relation to the AVAi $\left(<0.6 \mathrm{~cm}^{2} / \mathrm{m}^{2}\right)$ [4]. MR was quantified in the apical long-axis view by measuring the MR jet area at mid-systole [4]. The severity of MR was graded by the MR jet area relative to the left atria area, as follows: none or trace; mild (MR jet area $<20 \%$ ); moderate (MR jet area $20-40 \%$ ); or severe (MR jet area $\geq 40 \%$ ). A morethan-moderate MR grade was considered clinically significant. In addition, the etiology of MR was classified into the following four groups, based on Carpentier's functional classification [10]: Type I, II, IIIa and IIIb.

\section{BAV procedures}

All procedures were performed under local anesthesia at the puncture site, using either an antegrade or retrograde approach. The antegrade trans-septal approach, using the INOUE balloon (TORAY, Japan), was performed as previously reported [11]. Briefly, the balloon devices were delivered using a $14 \mathrm{Fr}$ catheter via the femoral vein, with temporary pacing delivered using an $6 \mathrm{Fr}$ catheter in the opposite femoral vein. A snare catheter, introduced via the radial artery, was secured to an extra-stiff, 0.032 in., guidewire, passing from the right femoral vein through the right atrium, left atrium, and left ventricle, and then across the aortic valve, providing sufficient support to deliver and control the balloon device. Systemic arterial pressure was monitored using a $5 \mathrm{Fr}$ pig tail catheter place in the ascending aorta via the other radial artery. Though the INOUE balloon was our first choice for the antegrade approach, in case of difficulty crossing the INOUE balloon, the VACS II (Osypka AG, Germany) or TYSHAK (NumED CANADA INC., Canada) were selected as an alternate. In the conventional retrograde arterial approach, either a VACS II, TYSHAK, MAXI LD (Cardinal health Japan, Japan), or MUSTANG (Boston Scientific Limited, Ireland) balloon was used, based on the surgeon's preference. The selected balloon was advanced from the femoral artery. The AcuNav (Siemens Medical Solutions, USA) was introduced using an $8 \mathrm{Fr}$ catheter in the jugular vein and used to guide atrial septum puncture, to observe the aortic valve during balloon inflation, and to monitor for complications, such as cardiac tamponade and aortic regurgitation. We performed contrast-enhanced multidetector computed tomography to measure the size and area of aortic annulus.

\section{Statistical analysis}

Continuous variables were expressed as mean values and standard deviation for normally distributed data, and as the median and interquartile range for nonnormally distributed data. Categorical variables were expressed as frequencies and percentages. Continuous parameters between subgroups were evaluated using Student's t test, with proportional differences 
evaluated using Fisher's exact test. Univariate logistic regression analysis was initially used to identify parameters associated with persisting significant MR at 3 months after BAV. Significant parameters were entered in a multivariate analysis, using a stepwise selection, to identify independent predictors of significant MR after BAV. The entry criterion for an individual item into the multivariable logistic regression model was $p<0.05$. For all steps, a $p$-value $<0.05$ was regarded as statistically significant. All analyses were performed using a commercially available software (MedCalc Statistical Software version 18.10, Mariakerke, Belgium).

\section{Results}

Patients' clinical and baseline characteristics

BAV was successfully completed, without major complication, in all 140 patients included in the analysis. Of the initial group of 140 patients, 57 (40.7\%) were not available for the 3 months follow-up due to death $(n=32)$, requiring subsequent SAVR $(n=7)$ or TAVR $(n=2)$, or lost to follow-up $(n=16)$. The echocardiography data at baseline and at 1 and 3 months after $\mathrm{BAV}$, for the remaining 83 patients included in our final analysis are shown in Fig. 1. The indications for BAV included a bridge-to-SAVR or -TAVR $(n=27)$, the intervention of choice $(n=27)$, risk reduction associated with non-cardiac surgery $(n=17)$, and for diagnostic purposes $(n=12)$. The baseline clinical and echocardiographic characteristics of the 83 patients forming our study group are reported in Table 1, with key features summarized as follows: mean age, $86.2 \pm 5.4$ years; 56 women (67.5\%); and mean LV ejection fraction (LVEF), $55.2 \pm 11.2 \%$. Severe aortic regurgitation was not identified in any of the patients before BAV.
Comparison of baseline characteristics between the MR and non-MR group

The MR group included 40 patients (48.2\%) classified as having more-than-moderate MR, with the other 43 patients (51.2\%) forming the non-MR group. The baseline clinical characteristics were similar for the MR and nonMR group, except that patients in the MR group were more likely to have a lower hemoglobin $(10.5 \pm 1.7 \mathrm{~g} / \mathrm{dL}$ versus $11.6 \pm 1.6 \mathrm{~g} / \mathrm{dL}, p=0.004)$, albumin $(3.2 \pm 0.5 \mathrm{~g} / \mathrm{dL}$ versus $3.5 \pm 0.5 \mathrm{~g} / \mathrm{dL}, p=0.010)$ and estimated glomerular filtration rate $\left(39.4 \pm 19.0 \mathrm{~mL} / \mathrm{min} / 1.73 \mathrm{~m}^{2}\right.$ versus $\left.50.4 \pm 20.1 \mathrm{~mL} / \mathrm{min} / 1.73 \mathrm{~m}^{2}, p=0.012\right)$, and a higher creatinine $(1.1(1.0-1.2) \mathrm{mg} / \mathrm{dL}$ versus $0.9(0.8-1.0) \mathrm{mg} / \mathrm{dL}$, $p=0.002)$ and brain natriuretic peptide (BNP) (702 (574-876) $\mathrm{pg} / \mathrm{mL}$ versus 216 (175-336) $\mathrm{pg} / \mathrm{mL}, \quad p<$ $0.001)$ levels. With regard to baseline echocardiography parameters, the two groups showed similar severity of AS, but with patients in the MR group being more likely to have a larger LV size (LV end-diastolic dimension, $46.2 \pm 6.0 \mathrm{~cm}$ versus $43.2 \pm 7.1 \mathrm{~cm}, p=0.039$; LV endsystolic dimension, $32.6 \pm 6.8 \mathrm{~cm}$ versus $28.9 \pm 7.0 \mathrm{~cm}$, $p=0.018)$ and lower LVEF $(51.4 \pm 13.0 \%$ versus $58.6 \pm$ $7.8 \%, p=0.003)$.

\section{Time course of change in clinical, laboratory and echocardiography parameters after BAV}

The time course of change in clinical, laboratory, and echocardiography parameters after BAV is shown in Table 2 and Table 3. All parameters of AS severity significantly improved at 1 and 3 months after BAV, in both the MR and non-MR groups. The prevalence of the New York Heart Association (NYHA) functional class III or IV markedly decreased in both groups at 1 and 3 months after BAV (MR group: $70 \%$ at baseline versus $2.5 \%$ (1 month) and $2.5 \%$ (2 months); non-MR group: $44.2 \%$ versus $4.5 \%$ versus $4.5 \%$, respectively; all $p<$

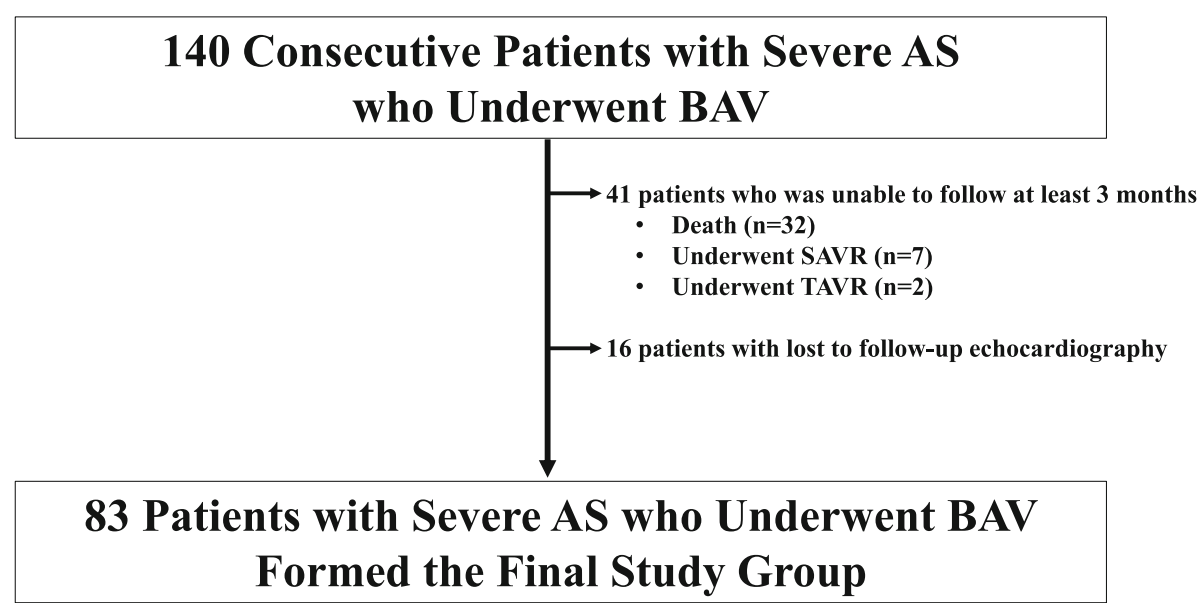

Fig. 1 Clinical and baseline characteristics for patients with severe aortic stenosis (AS) treated using balloon aortic valvuloplasty (BAV) SAVR, aortic valve replacement; TAVR, transcatheter aortic valve replacement 
Table 1 Baseline Clinical and Echocardiography Characteristics

\begin{tabular}{|c|c|c|c|c|}
\hline Variables & All $(n=83)$ & MR group $(n=40)$ & Non-MR group $(n=43)$ & $P$ value \\
\hline \multicolumn{5}{|l|}{ Clinical data } \\
\hline Age, years & $86.2 \pm 5.4$ & $86.1 \pm 6.5$ & $86.4 \pm 4.1$ & 0.819 \\
\hline Female, $n(\%)$ & $56(67.5)$ & $25(62.5)$ & $31(72.1)$ & 0.482 \\
\hline Body surface area, $\mathrm{m}^{2}$ & $1.4 \pm 0.2$ & $1.4 \pm 0.2$ & $1.4 \pm 0.2$ & 0.821 \\
\hline Body mass index, $\mathrm{kg} / \mathrm{m}^{2}$ & $21.0 \pm 3.4$ & $20.8 \pm 3.6$ & $21.2 \pm 3.3$ & 0.623 \\
\hline NYHA III/IV, n (\%) & $47(60.2)$ & $28(70.0)$ & $19(44.2)$ & 0.094 \\
\hline STS score, \% & $9.6 \pm 6.9$ & $11.1 \pm 7.5$ & $8.2 \pm 6.0$ & 0.051 \\
\hline \multicolumn{5}{|l|}{ Comorbidities, $n$ (\%) } \\
\hline Hypertension & $63(75.9)$ & $29(72.5)$ & $34(79.1)$ & 0.609 \\
\hline Diabetes mellitus & $24(28.9)$ & $13(32.5)$ & $11(25.6)$ & 0.629 \\
\hline Dyslipidemia & $31(37.3)$ & $12(30.0)$ & $19(44.2)$ & 0.256 \\
\hline History of smoking & $11(13.3)$ & $5(12.5)$ & $6(14.0)$ & 1.000 \\
\hline Coronary artery diseases & $13(15.7)$ & $8(20.0)$ & $5(11.6)$ & 0.371 \\
\hline Peripheral arterial diseases & $8(9.6)$ & $5(12.5)$ & $3(7.0)$ & 0.473 \\
\hline Cerebrovascular diseases & $11(13.3)$ & $7(17.5)$ & $4(9.3)$ & 0.340 \\
\hline Atrial fibrillation & $26(31.3)$ & $17(42.5)$ & $9(20.9)$ & 0.057 \\
\hline \multicolumn{5}{|l|}{ Approach for BAV, $n$ (\%) } \\
\hline Antegrade BAV & $65(78.3)$ & $29(72.5)$ & 36 (83.7) & 0.288 \\
\hline Previous BAV & $12(14.5)$ & $5(12.5)$ & $7(16.3)$ & 0.758 \\
\hline \multicolumn{5}{|l|}{ Laboratory data } \\
\hline Hemoglobin, g/dL & $11.0 \pm 1.7$ & $10.5 \pm 1.7$ & $11.6 \pm 1.6$ & 0.004 \\
\hline Albumin, g/dL & $3.4 \pm 0.5$ & $3.2 \pm 0.5$ & $3.5 \pm 0.5$ & 0.010 \\
\hline Creatinine, mg/dL & $1.0(0.8-1.2)$ & $1.1(0.9-1.5)$ & $0.9(0.7-1.0)$ & 0.002 \\
\hline $\mathrm{eGFR}, \mathrm{mL} / \mathrm{min} / 1.73 \mathrm{~m}^{2}$ & $45.1 \pm 20.3$ & $39.4 \pm 19.0$ & $50.4 \pm 20.1$ & 0.012 \\
\hline $\mathrm{BNP}, \mathrm{pg} / \mathrm{mL}$ & $377(167-758)$ & 702 (391-1042) & $216(112-422)$ & $<0.001$ \\
\hline \multicolumn{5}{|l|}{ Medications, $n$ (\%) } \\
\hline$\beta$-blocker & $52(62.7)$ & $26(65.0)$ & $26(60.5)$ & 0.821 \\
\hline ACEI/ARB & $57(68.7)$ & $26(65.0)$ & $31(72.1)$ & 0.636 \\
\hline Statin & $33(39.8)$ & $12(30.0)$ & $21(48.8)$ & 0.116 \\
\hline$C C B$ & $34(41.0)$ & $9(22.5)$ & $25(58.1)$ & 0.002 \\
\hline Loop diuretics & $48(57.8)$ & $25(62.5)$ & $23(53.5)$ & 0.506 \\
\hline MRA & $22(26.5)$ & $11(27.5)$ & $11(25.6)$ & 1.000 \\
\hline Tolvaptan & $6(7.2)$ & $5(12.5)$ & $1(2.3)$ & 0.101 \\
\hline Anticoagulant & $15(18.1)$ & $8(20.0)$ & $7(16.3)$ & 0.778 \\
\hline Antiplatelet & $22(26.5)$ & $11(27.5)$ & $11(25.6)$ & 1.000 \\
\hline \multicolumn{5}{|c|}{ Echocardiography parameters } \\
\hline \multicolumn{5}{|l|}{ Conventional parameters } \\
\hline LVEDD, mm & $44.6 \pm 6.7$ & $46.2 \pm 6.0$ & $43.2 \pm 7.1$ & 0.039 \\
\hline LVESV, mm & $30.7 \pm 7.1$ & $32.6 \pm 6.8$ & $28.9 \pm 7.0$ & 0.018 \\
\hline LVEF, \% & $55.2 \pm 11.2$ & $51.4 \pm 13.0$ & $58.6 \pm 7.8$ & 0.003 \\
\hline LVSVI, mL & $41.6 \pm 12.9$ & $38.3 \pm 11.7$ & $44.7 \pm 13.2$ & 0.023 \\
\hline IVST, mm & $10.8 \pm 2.3$ & $10.7 \pm 2.1$ & $10.9 \pm 2.4$ & 0.574 \\
\hline PWT, mm & $10.5 \pm 2.1$ & $10.5 \pm 2.0$ & $10.5 \pm 2.2$ & 0.983 \\
\hline E/A & $0.94 \pm 0.58$ & $1.1 \pm 0.6$ & $0.8 \pm 0.6$ & 0.089 \\
\hline
\end{tabular}


Table 1 Baseline Clinical and Echocardiography Characteristics (Continued)

\begin{tabular}{|c|c|c|c|c|}
\hline Variables & All $(n=83)$ & MR group $(n=40)$ & Non-MR group $(n=43)$ & $P$ value \\
\hline$E / e^{\prime}$ & $19.15 \pm 8.21$ & $20.37 \pm 8.59$ & $18.03 \pm 7.78$ & 0.203 \\
\hline TR-PG, mmHg & $33.8 \pm 14.2$ & $40.5 \pm 15.4$ & $33.4 \pm 12.2$ & 0.023 \\
\hline$A R \geq$ moderate, $n(\%)$ & $8(9.6)$ & $5(12.5)$ & $3(7.0)$ & 0.473 \\
\hline \multicolumn{5}{|l|}{ AS parameters } \\
\hline AVA, $\mathrm{cm}^{2}$ & $0.68 \pm 0.16$ & $0.66 \pm 0.17$ & $0.70 \pm 0.15$ & 0.301 \\
\hline AVAi, $\mathrm{cm}^{2} / \mathrm{m}^{2}$ & $0.48 \pm 0.11$ & $0.47 \pm 0.12$ & $0.49 \pm 0.10$ & 0.401 \\
\hline Peak V, m/s & $3.95 \pm 0.85$ & $3.81 \pm 0.87$ & $4.08 \pm 0.81$ & 0.147 \\
\hline $\mathrm{mPG}, \mathrm{mmHg}$ & $37.4 \pm 16.3$ & $35.6 \pm 17.0$ & $39.1 \pm 15.6$ & 0.330 \\
\hline \multicolumn{5}{|l|}{ MR parameters } \\
\hline MR jet area, $\mathrm{cm}^{2}$ & $4.1 \pm 3.6$ & $7.0 \pm 2.9$ & $1.4 \pm 1.2$ & $<0.001$ \\
\hline$\% \mathrm{MR}, \%$ & $20.6 \pm 16.5$ & $34.0 \pm 13.1$ & $8.1 \pm 6.5$ & $<0.001$ \\
\hline \multicolumn{5}{|l|}{ Etiology of MR } \\
\hline Type I & 16 & 16 & - & - \\
\hline Type II & 5 & 5 & - & - \\
\hline Type IIla & 10 & 10 & - & - \\
\hline Type IIlb & 9 & 9 & - & - \\
\hline
\end{tabular}

Data are mean \pm SD for normally distributed data and median and interquartile range for non-normally distributed data, or $\mathrm{n}$ (\%)

$N Y H A$, New York Heart Association, BAV, balloon aortic valvuloplasty, eGFR, estimated glomerular filtration rate, $B N P$ brain natriuretic peptide, $A C E I$ angiotensin converting enzyme inhibitor, $A R B$ angiotensin II receptor blocker, CCB Calcium channel blocker, MRA mineral corticoid receptor antagonist, $L V E D D$ left ventricular end-diastolic dimension, LVESV left ventricular end-systolic dimension, LVEF left ventricular ejection fraction, LV left ventricular, SVI stroke volume index, IVST interventricular septum thickness, $P W T$ posterior wall thickness, $E$ early diastolic wave velocity, $A$ atrial wave velocity, $e^{\prime}$ early diastolic mitral annular velocity, $T R-P G$ peak trans-tricuspid pressure gradient, $A S$ aortic stenosis, AVA aortic valve area, AVAi indexed aortic valve area, Peak $V$ peak trans-aortic velocity, $m P G$ mean transaortic pressure gradient, $A R$ aortic regurgitation, $M R$ mitral regurgitation, $\% M R$ MR jet area of left atrial area

0.001). The changes in all NYHA functional class 1 month and 3 months after BAV in the MR and non-MR group are shown in Fig. 2. The BNP level significantly decreased in the MR group, both at 1 month (from 702 $\mathrm{pg} / \mathrm{mL}$ to $421 \mathrm{pg} / \mathrm{mL} ; p=0.002$ ) and 3 months after BAV (from $702 \mathrm{pg} / \mathrm{mL}$ to $281 \mathrm{pg} / \mathrm{mL} ; p<0.001$ ), but not in the non-MR group. The LV size was significantly reduced at 3 months after BAV in the MR group (LV enddiastolic dimension, $46.2 \pm 6.0 \mathrm{~cm}$ versus $44.0 \pm 6.8 \mathrm{~cm}$, $p=0.03$; LV end-systolic dimension, $32.6 \pm 6.8 \mathrm{~cm}$ versus $28.6 \pm 7.0 \mathrm{~cm}, \mathrm{p}<0.001$ ), but not in the non-MR group. The LVEF significantly improved at 3 months after BAV in both groups.

\section{Predictors of persisting significant MR at 3 months after BAV}

MR significantly improved both 1 and 3 months after BAV in the MR group, but not in the non-MR group (Fig. 3). In the MR group, the MR jet area at baseline was $6.3 \mathrm{~cm}^{2}\left(4.5-9.7 \mathrm{~cm}^{2}\right)$, and which gradually decreased at 1 month $\left(3.5 \mathrm{~cm}^{2}, 1.5-7.4 \mathrm{~cm}^{2}\right)$ and at 3 months $(2.1$ $\mathrm{cm}^{2}, 1.1-6.0 \mathrm{~cm}^{2}$ ) after BAV. In addition, MR tended to improve after BAV regardless of the etiology of MR in the MR group, with the improvement being significant for patients in every etiology of MR (Fig. 4). At 3 months after BAV, significant MR persisted in 15 patients in the MR group. In 40 patients of the MR group, 25 patients
(62.5\%) improved MR jet area $<4.0 \mathrm{~cm}^{2}$ and 9 patients (22.5\%) improved but remained significant MR, and 6 patients (15.0\%) worsened MR compared with baseline. Categorized by MR etiology, persisted significant MR was showed $7 / 16(43.8 \%)$ in Type I, 2/5 (40\%) in Type II, 4/10 (40\%) in Type IIIa, and 2/9 (22.2\%) in Type IIIb. Though Type IIIb were tended to achieve much more reduction of $\mathrm{MR}$, there was no significant difference among each etiology groups. The odds ratio (OR) and 95\% confidence interval (CI) for univariate and multivariate logistic regression analysis of the variables associated with a persisting significant MR are summarized in Table 4. On multivariate logistic regression analysis, the change at 1 month, from baseline, in the LV end-systolic dimension (OR: 1.36; 95\% CI: 1.05-1.76; $P=0.022$ ) and MR jet area (OR: $1.95 ; 95 \%$ CI: $1.16-3.29 ; P=0.012$ ) were retained as independent predictive factors of persisting significant MR at 3 months after BAV.

\section{Discussion}

We report significant improvement in MR after BAV in patients with severe AS, with the change in LV endsystolic dimension 1 month after BAV, from baseline, being independently associated with remaining significant MR 3 months after BAV. In addition, improvement in heart failure status after BAV tended to be more 
Table 2 Time Course of Parameters after BAV in the MR Group

\begin{tabular}{|c|c|c|c|c|c|}
\hline & Baseline & 1 month after BAV & $P$ value & 3 months after BAV & $P$ value \\
\hline \multicolumn{6}{|l|}{ Clinical data } \\
\hline NYHA III/IV, n (\%) & $28(70.0)$ & $1(2.5)$ & $<0.001$ & $1(2.5)$ & $<0.001$ \\
\hline \multicolumn{6}{|l|}{ Laboratory data } \\
\hline BNP, pg/mL & $702(391-1042)$ & $421(206-618)$ & 0.002 & $281(182-401)$ & $<0.001$ \\
\hline \multicolumn{6}{|l|}{ Conventional echo parameters } \\
\hline LVEDD, mm & $46.2 \pm 6.0$ & $45.4 \pm 6.5$ & 0.237 & $44.0 \pm 6.8$ & 0.033 \\
\hline LVESD, mm & $32.6 \pm 6.8$ & $31.2 \pm 7.7$ & 0.148 & $28.6 \pm 7.0$ & $<0.001$ \\
\hline LVEF, \% & $51.4 \pm 13.0$ & $54.1 \pm 10.1$ & 0.089 & $57.4 \pm 12.5$ & 0.007 \\
\hline LVSVI, mL & $38.3 \pm 11.7$ & $41.3 \pm 11.1$ & 0.052 & $44.6 \pm 11.2$ & 0.002 \\
\hline E/A & $1.0(0.6-1.6)$ & $0.7(0.6-1.0)$ & 0.003 & $0.7(0.5-0.9)$ & 0.001 \\
\hline$E / e^{\prime}$ & $20.5 \pm 8.7$ & $15.5 \pm 6.2$ & $<0.001$ & $16.1 \pm 7 b n p .1$ & 0.002 \\
\hline TR-PG, mmHg & $40.5 \pm 15.4$ & $29.7 \pm 8.4$ & $<0.001$ & $28.9 \pm 6.4$ & $<0.001$ \\
\hline$A R \geq$ moderate, $n(\%)$ & $5(12.5)$ & $6(15.0)$ & 1.000 & $4(10.0)$ & 1.000 \\
\hline \multicolumn{6}{|l|}{ AS parameters } \\
\hline AVA, $\mathrm{cm}^{2}$ & $0.66 \pm 0.17$ & $0.84 \pm 0.19$ & $<0.001$ & $0.80 \pm 0.20$ & 0.001 \\
\hline AVAi, $\mathrm{cm}^{2} / \mathrm{m}^{2}$ & $0.47 \pm 0.12$ & $0.59 \pm 0.12$ & $<0.001$ & $0.57 \pm 0.12$ & $<0.001$ \\
\hline Peak V, m/s & $61.0 \pm 27.1$ & $45.0 \pm 19.1$ & $<0.001$ & $51.7 \pm 25.1$ & 0.002 \\
\hline mPG $(m m H g)$ & $35.6 \pm 17.0$ & $24.9 \pm 11.5$ & $<0.001$ & $29.8 \pm 15.2$ & 0.003 \\
\hline \multicolumn{6}{|l|}{ MR parameters } \\
\hline MR jet area, $\mathrm{cm}^{2}$ & $6.3(4.5-9.7)$ & $3.5(1.5-7.4)$ & $<0.001$ & $2.1(1.1-6.0)$ & $<0.001$ \\
\hline$\% \mathrm{MR}, \%$ & $33.3(22.6-42.7)$ & $16.0(8.9-34.3)$ & $<0.001$ & $12.0(4.7-29.4)$ & $<0.001$ \\
\hline Mitral annular dimension, $\mathrm{mm}$ & $28.5 \pm 4.9$ & $27.2 \pm 4.2$ & 0.030 & $25.5 \pm 3.3$ & $<0.001$ \\
\hline Tenting height, mm & $4.1 \pm 1.9$ & $3.8 \pm 1.9$ & 0.307 & $2.8 \pm 1.1$ & $<0.001$ \\
\hline Tenting area, $\mathrm{mm}^{2}$ & $58.8 \pm 31.6$ & $52.0 \pm 28.5$ & 0.169 & $35.5 \pm 14.5$ & $<0.001$ \\
\hline
\end{tabular}

prominent among patients with severe AS and significant MR.

\section{Place of BAV in the TAVR era}

BAV was first proposed in 1986, offering an alternative to conventional SAVR in elderly and frail patients with severe AS for whom there were no other effective options [3]. However, the hemodynamic improvement was reported to be short-lived, with rapid restenosis, with treatment outcomes being as poor as for patients not treated for severe AS $[3,12,13]$. Despite these limitations, BAV as a possible therapeutic intervention is considered for patients with severe AS and significant comorbidities which limits the use of a surgical cardiac intervention, such as chronic kidney disease, peripheral vascular disease, and coronary artery disease. With the aging of the general population, there is an increasing prevalence of elderly and frail patients presenting with severe AS for whom BAV can provide a beneficial therapeutic intervention, expanding the indications for BAV, despite the TAVR era [14]. In this study, we demonstrate that good clinical outcomes can be achieved at 1 and 3 months after BAV, including an improvement in cardiac status among patients with severe AS and significant MR.

\section{MR in patients with severe AS}

MR is commonly observed in patients with severe AS [5]. In patients with severe AS, the mitral annulus, leaflets, and sub-valvular apparatus are often calcified, to varying degrees, while the LV size and function are typically normal. Occasionally, patients with AS are observed to have mitral valve prolapse or a flail leaflet, which are normally associated with mitral annular calcification. Ideally, simultaneous surgical replacement of both the aortic and mitral valve would be the preferred treatment for severe AS and significant MR; however, this surgical strategy increases the risk of morbidity and mortality, especially for elderly patients [15]. Whereas isolated SAVR in elderly patients is associated with an acceptable mortality rate, the surgical risk is significantly increased when double valve surgery is performed, with or without revascularization. The Euro Heart Survey on Valvular Heart Disease, in fact, reported a perioperative mortality rate of $6.5 \%$ for double valve intervention, 
Table 3 Time Course of Parameters after BAV in the Non-MR Group

\begin{tabular}{|c|c|c|c|c|c|}
\hline & Baseline & 1 month after BAV & $P$ value & 3 months after BAV & $P$ value \\
\hline \multicolumn{6}{|l|}{ Clinical data } \\
\hline NYHA III/IV, n (\%) & $19(44.2)$ & $2(4.5)$ & $<0.001$ & $2(4.5)$ & $<0.001$ \\
\hline \multicolumn{6}{|l|}{ Laboratory data } \\
\hline$B N P, p g / m L$ & $216(112-422)$ & $201(103-405)$ & 0.293 & $171(11-368)$ & 0.086 \\
\hline \multicolumn{6}{|l|}{ Conventional echo parameters } \\
\hline LVEDD, mm & $43.2 \pm 7.1$ & $42.8 \pm 6.4$ & 0.680 & $42.8 \pm 6.4$ & 0.659 \\
\hline LVESD, mm & $28.9 \pm 7.0$ & $28.0 \pm 6.9$ & 0.230 & $27.4 \pm 5.8$ & 0.091 \\
\hline LVEF, \% & $58.6 \pm 7.8$ & $59.8 \pm 8.8$ & 0.318 & $61.4 \pm 7.8$ & 0.024 \\
\hline LVSVI, mL & $44.7 \pm 13.2$ & $49.0 \pm 13.5$ & 0.016 & $49.3 \pm 14.7$ & 0.009 \\
\hline E/A & $0.7(0.5-0.9)$ & $0.7(0.5-0.9)$ & 0.435 & $0.7(0.5-0.8)$ & 0.610 \\
\hline$E / e^{\prime}$ & $17.8 \pm 7.8$ & $17.5 \pm 8.2$ & 0.692 & $18.0 \pm 9.9$ & 0.918 \\
\hline TR-PG, mmHg & $33.4 \pm 12.1$ & $31.2 \pm 13.5$ & 0.138 & $30.6 \pm 11.4$ & 0.151 \\
\hline AR $\geq$ moderate, $n(\%)$ & $3(7.0)$ & $4(9.5)$ & 0.713 & $6(14.0)$ & 0.483 \\
\hline \multicolumn{6}{|l|}{ AS parameters } \\
\hline AVA, $\mathrm{cm}^{2}$ & $0.70 \pm 0.15$ & $0.88 \pm 0.20$ & $<0.001$ & $0.84 \pm 0.20$ & $<0.001$ \\
\hline AVAi, $\mathrm{cm}^{2} / \mathrm{m}^{2}$ & $0.48 \pm 0.10$ & $0.62 \pm 0.14$ & $<0.001$ & $0.59 \pm 0.13$ & $<0.001$ \\
\hline Peak V, m/s & $69.1 \pm 27.0$ & $53.1 \pm 23.1$ & $<0.001$ & $57.0 \pm 23.8$ & 0.001 \\
\hline mPG $(\mathrm{mmHg})$ & $39.1 \pm 15.6$ & $30.9 \pm 14.2$ & $<0.001$ & $32.5 \pm 14.3$ & $<0.001$ \\
\hline \multicolumn{6}{|l|}{ MR parameters } \\
\hline MR jet area, $\mathrm{cm}^{2}$ & $1.0(0.3-2.5)$ & $0.7(0.2-1.8)$ & 0.627 & $0.9(0.3-2.1)$ & 0.943 \\
\hline$\% \mathrm{MR}, \%$ & $7.3(2.0-12.9)$ & $4.9(1.2-11.3)$ & 0.472 & $4.1(1.7-12.2)$ & 0.801 \\
\hline Mitral annular dimension, mm & $25.8 \pm 3.1$ & $23.8 \pm 3.4$ & 0.001 & $24.7 \pm 3.3$ & 0.074 \\
\hline Tenting height, mm & $3.6 \pm 1.6$ & $3.0 \pm 1.5$ & 0.047 & $3.0 \pm 1.7$ & 0.052 \\
\hline Tenting area, $\mathrm{mm}^{2}$ & $46.9 \pm 24.0$ & $36.5 \pm 21.1$ & 0.015 & $37.9 \pm 25.9$ & 0.052 \\
\hline
\end{tabular}

Data are mean \pm SD for normally distributed data and median and interquartile range for non-normally distributed data, or $n(\%)$ Abbreviations as in Table 1

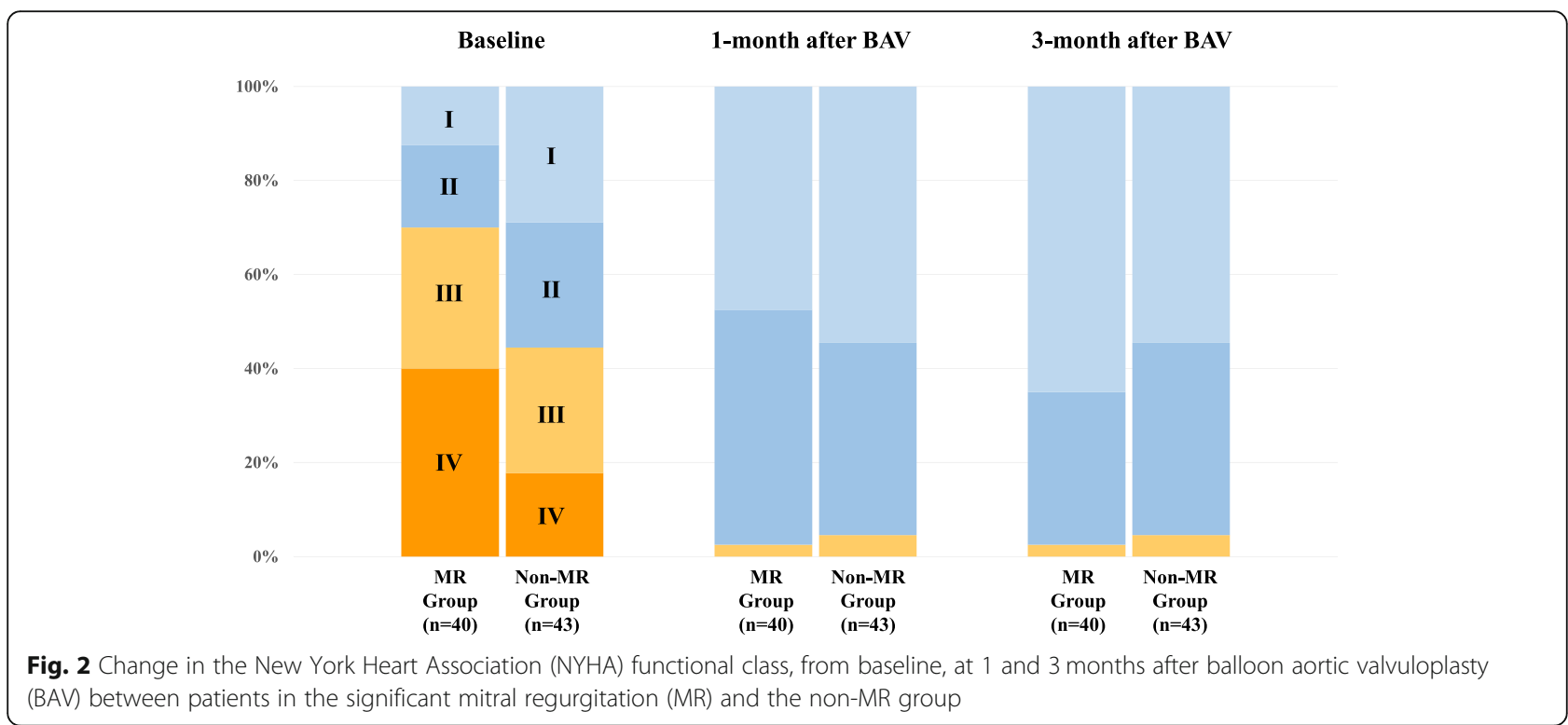




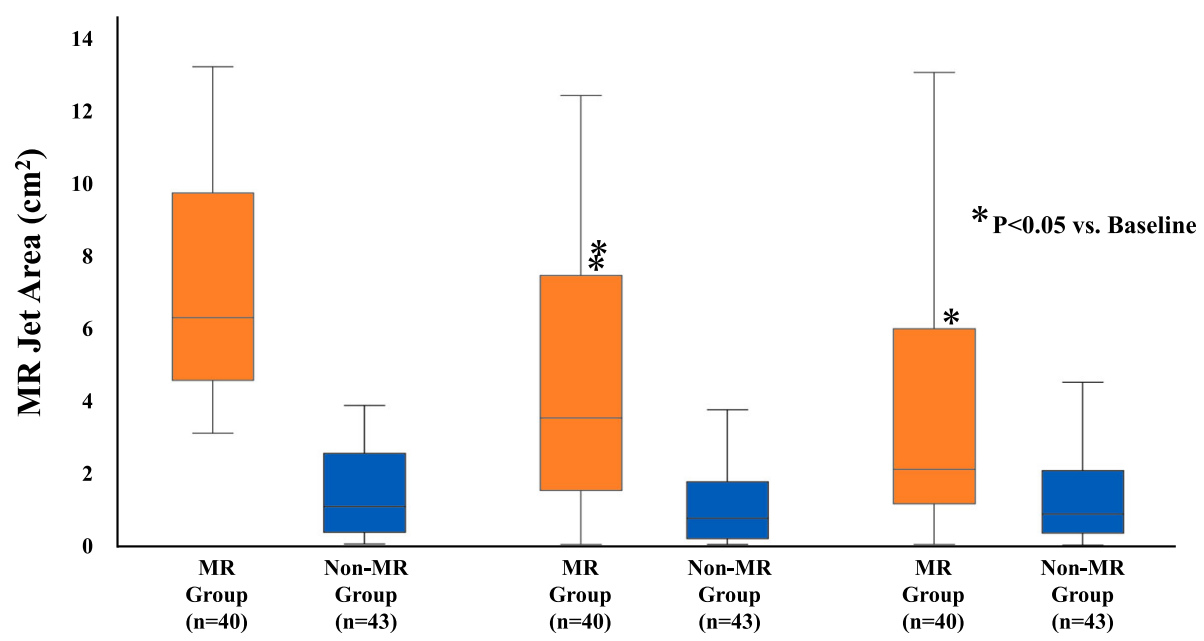

Fig. 3 Change in mitral regurgitation (MR), from baseline, at 1 and 3 months after balloon aortic valvuloplasty (BAV) in the significant mitral regurgitation (MR) and the non-MR group, showing a significant improvement at both 1 and 3 months in the MR, but not the non-MR, group

compared to $2.7 \%$ for isolated SAVR and $4.3 \%$ for SAVR combined with revascularization [16].

The resolution of AS by means of SAVR or TAVR leads to an immediate drop in the LV systolic pressure, which reduces the pressure gradient across the mitral valve and, therefore, should improve MR severity. In the presence of secondary MR with mitral valve tethering, the resolution of the AS can reduce the mitral tenting area in the acute phase, which in turn leads to a decrease in MR severity. Coutinho et al. reported a 4.9 -fold increase in the risk of mortality for patients in whom MR failed to improve after isolated SAVR [6]. Harling et al.

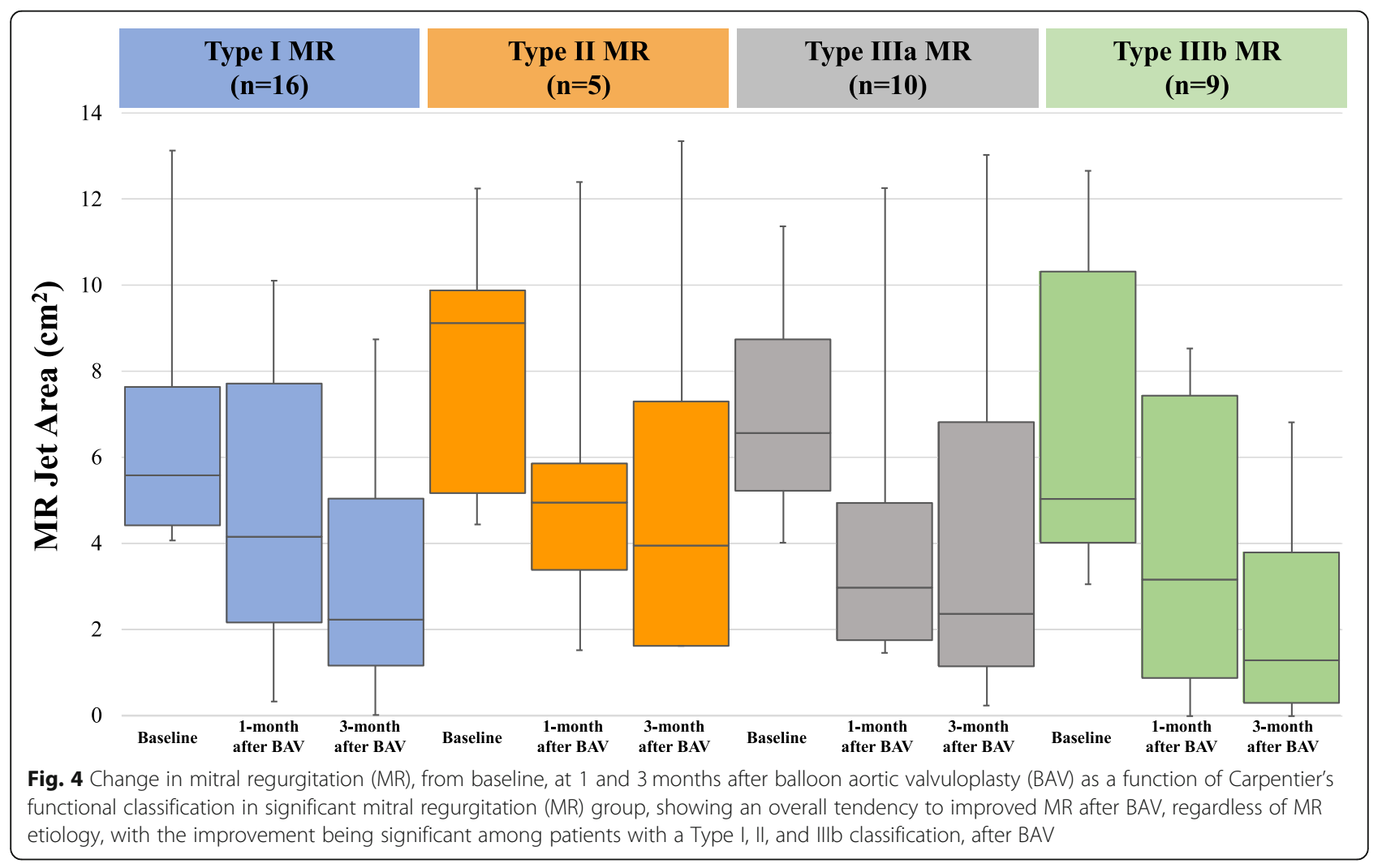


Table 4 Univariate and Multivariate Analysis for Predicting Remaining Significant MR at 3-Month after BAV

\begin{tabular}{|c|c|c|c|c|c|c|}
\hline \multirow[t]{2}{*}{ Variables } & \multicolumn{3}{|c|}{ Univariate analysis } & \multicolumn{3}{|c|}{ Multivariate analysis } \\
\hline & $\mathrm{OR}$ & $95 \% \mathrm{Cl}$ & $P$ value & OR & $95 \% \mathrm{Cl}$ & $P$ value \\
\hline \multicolumn{7}{|c|}{ Baseline parameters } \\
\hline Age & 1.00 & $0.91-1.11$ & 0.940 & & & \\
\hline Female & 1.86 & $0.50-6.94$ & 0.356 & & & \\
\hline BNP & 1.00 & $1.00-1.00$ & 0.130 & & & \\
\hline NYHA III/IV & 1.29 & $0.31-5.35$ & 0.722 & & & \\
\hline LVESD & 0.96 & $0.87-1.06$ & 0.469 & & & \\
\hline TR-PG & 0.98 & $0.94-1.03$ & 0.447 & & & \\
\hline AVAi & 9.80 & $0.04-2225.02$ & 0.410 & & & \\
\hline LVEF & 1.03 & $0.98-1.09$ & 0.253 & & & \\
\hline MR jet area & 1.21 & $0.96-1.53$ & 0.105 & & & \\
\hline$E / e^{\prime}$ & 1.01 & $0.93-1.09$ & 0.867 & & & \\
\hline \multicolumn{7}{|c|}{ Change between baseline and 1-month after BAV } \\
\hline$\triangle$ LVESD & 1.20 & $1.04-1.40$ & 0.015 & 1.36 & $1.05-1.76$ & 0.022 \\
\hline$\triangle \mathrm{TR}-\mathrm{PG}$ & 1.05 & $1.00-1.11$ & 0.067 & & & \\
\hline$\Delta \mathrm{MR}$ jet area & 1.31 & $1.05-1.62$ & 0.016 & 1.95 & $1.16-3.29$ & 0.012 \\
\hline$\triangle \mathrm{AVAi}$ & 0.04 & $0.00-130.06$ & 0.443 & & & \\
\hline$\triangle \mathrm{LVEF}$ & 0.99 & $0.93-1.06$ & 0.835 & & & \\
\hline$\Delta \mathrm{E} / \mathrm{e}^{\prime}$ & 1.03 & $0.94-1.12$ & 0.510 & & & \\
\hline
\end{tabular}

Abbreviations as in Table 1 and 2

also reported poorer early and late outcomes associated with moderate-to-severe MR left untreated at the time of SAVR [7]. In addition, the PARTNER trial reported an improvement in MR in the majority of patients after SAVR and TAVR (69.4 and 57.7\%, respectively), but with a worsening of MR severity in 2.8 and $5.8 \%$, respectively, of patients treated using SAVR and TAVR [8]. Although hemodynamic success of SAVR or TAVR would be expected to improve MR severity, other factors can potentially negatively affect MR severity, with the following having been identified after TAVR: [17, 18] presence of atrial fibrillation; left bundle branch block or right ventricular pacing; ischemic wall motion abnormalities; and self-expanding valve with deep implant. However, the mechanism underlying changes in MR after SAVR or TAVR and identification of patients for whom SAVR or TAVR may be effective to improve MR remain uncertain. Furthermore, studies to date have not generally reported on the mechanism or etiology of MR in patients who have undergone SAVR or TAVR.

\section{Difference among the etiology of MR}

In this study, the reduction of LV cavity was the predictor of MR improvement. The effect for Type I and IIIb were recognizable, but Type II and IIIa which were leaflet issues were unclear. Though we could not find the statistically difference among the MR etiology in this small number study, it seems to be tendency of poor response in Type II and IIIa (Fig. 4). On the other hand, even in Type II and IIIa cases showed significant decreasing of the MR severity at 1 month and 3 months after BAV. This finding can bring great clinical worth for too sick elderly patients with AS and MR because $\mathrm{BAV}$ is less invasive, easy-to-use and low cost treatment.

\section{Clinical implications}

In this study, we report a significant improvement in MR after BAV in patients with severe AS, regardless of MR etiology. Importantly, improvement in heart failure status, such as BNP level or NYHA functional class, tended to be more prominent among patients with severe AS and significant baseline MR. Therefore, our findings support BAV as a potentially beneficial therapy for elderly patients with severe AS, and those with significant MR more specifically, who are not candidates for SAVR or TAVR because of comorbidity. In this study, we demonstrate that good efficacy for severe AS with MR can be achieved at 1 and 3 months after BAV. Moreover, the mortality rate even within 3 months after BAV was as high as $22.8 \%$ in this study, but most of them were non-cardiac death (78\%).

\section{Limitations}

This is a retrospective study, including a small number of patients from a single-center. Therefore, prospective studies, involving larger numbers of patients from different centers, are required to verify our findings. Moreover, the Awaji Medical Center is not currently accredited for TAVR; thus, $>40$ BAVs are performed annually at our center, which may have introduced some bias in the indications for BAV for patients with severe AS. Our patients who were cardiogenic shock, acute decompensated heart failure or required non-cardiac surgery were good indication for BAV, otherwise Although elective cases in this study such as cardiogenic shock, acute decompensated heart failure, or immediately required non-cardiac surgery $(62.1 \%)$ may undergo primary TAVR in the hospital accredited for TAVR, such patients were good indication for BAV as well.

\section{Conclusions}

Significant improvement of MR was observed among patients with severe AS who underwent BAV. Improvement of patients' heart failure status after BAV tended to be more prominent among patients with severe AS and significant MR. BAV can be useful as a therapeutic strategy for elderly patients with severe AS, especially those with significant MR, who are not candidates for SAVR or TAVR because of comorbidity. 


\section{Abbreviations}

AVAi: Aortic valve area estimated using the continuity equation and normalized to the body surface area; AS: Aortic stenosis; BAV: Balloon aortic valvuloplasty; BNP: Brain natriuretic peptide; NYHA: New York Heart Association; LV: Left ventricular; LVEF: Left ventricular ejection fraction; MR: Mitral regurgitation; SAVR: Surgical aortic valve replacement; TAVR: Transcatheter aortic valve replacement

\section{Acknowledgements}

We are grateful for the support of the entire staff of the Awaji Medical Center.

\section{Authors' contributions}

$\mathrm{RM}$ and $\mathrm{MI}$ designed the study, carried out subject recruitment, performed echocardiography, analysed the data, and wrote the manuscript. AY performed biventricular pacemaker implantation. TH, SO, WF, KK, YH, TI, HO, $\mathrm{MO}$ and $\mathrm{TH}$ assisted recruitment and manuscript revision. $\mathrm{HT}$ and $\mathrm{KH}$ assisted in study design, data interpretation and manuscript revision. All authors read and approved the final manuscript.

\section{Funding}

All the authors do not receive any founding related to this manuscript.

\section{Availability of data and materials}

Authors do not wish to share their data. All the data published in original paper belongs to Awaji Medical Center.

\section{Ethics approval and consent to participate}

Our study was approved by the ethics committee of Awaji Medical Center (No. 30-59), and the need for patient consent was waived due to the retrospective design of the study.

\section{Consent for publication}

Not applicable.

\section{Competing interests}

The authors declare that they have no competing interests to declare.

\section{Author details}

1Department of Cardiology, Hyogo Prefectural Awaji Medical Center, Sumoto, Japan. ${ }^{2}$ Division of Cardiovascular Medicine, Department of Internal Medicine, Kobe University Graduate School of Medicine, 7-5-2, Kusunoki-cho, Chuo-ku, Kobe 650-0017, Japan.

Received: 18 January 2020 Accepted: 2 April 2020

Published online: 13 April 2020

\section{References}

1. Davies SW, Gershlick AH, Balcon R. Progression of valvar aortic stenosis: a long-term retrospective study. Eur Heart J. 1991;12(1):10-4.

2. Alskaf $E$, Kardos A. The mystery of defining aortic valve area: what have we learnt from three-dimensional imaging modalities? J Echocardiogr. 2018, 16(3):130-8.

3. Cribier A, Savin T, Saoudi N, Rocha P, Berland J, Letac B. Percutaneous transluminal valvuloplasty of acquired aortic stenosis in elderly patients: an alternative to valve replacement? Lancet (London, England) 1986:1(8472):63-7.

4. Nishimura RA, Otto CM, Bonow RO, Carabello BA, Erwin JP 3rd, Fleisher LA, Ineid H, Mack MJ, McLeod CJ, O'Gara PT, et al. AHA/ACC focused update of the 2014 AHA/ACC guideline for the Management of Patients with Valvular Heart Disease: a report of the American College of Cardiology/American Heart Association task force on clinical practice guidelines. J Am Coll Cardiol. 2017:70(2):252-89.

5. Moazami N, Diodato MD, Moon MR, Lawton JS, Pasque MK, Herren RL, Guthrie TJ, Damiano RJ. Does functional mitral regurgitation improve with isolated aortic valve replacement? J Card Surg. 2004;19(5):444-8.

6. Coutinho GF, Correia PM, Pancas R, Antunes MJ. Management of moderate secondary mitral regurgitation at the time of aortic valve surgery. Eur J Cardio-Thoracic Surg. 2013;44(1):32-40.

7. Harling L, Saso S, Jarral OA, Kourliouros A, Kidher E, Athanasiou T. Aortic valve replacement for aortic stenosis in patients with concomitant mitral regurgitation: should the mitral valve be dealt with? Eur J Cardio-Thoracic Surg. 2011:40(5):1087-96.

8. Barbanti M, Webb JG, Hahn RT, Feldman T, Boone RH, Smith CR, Kodali S, Zajarias A, Thompson CR, Green P, et al. Impact of preoperative moderate/severe mitral regurgitation on 2-year outcome after transcatheter and surgical aortic valve replacement: insight from the placement of aortic Transcatheter valve (PARTNER) trial cohort a. Circulation. 2013;128(25):2776-84.

9. Lang RM, Badano LP, Mor-Avi V, Afilalo J, Armstrong A, Ernande L, Flachskampf FA, Foster E, Goldstein SA, Kuznetsova T, et al. Recommendations for cardiac chamber quantification by echocardiography in adults: an update from the American Society of Echocardiography and the European Association of Cardiovascular Imaging. Eur Heart J Cardiovasc Imaging. 2015;16(3):233-70.

10. Carpentier A, Chauvaud S, Fabiani JN, Deloche A, Relland J, Lessana A, D'Allaines C, Blondeau P, Piwnica A, Dubost C. Reconstructive surgery of mitral valve incompetence: ten-year appraisal. J Thorac Cardiovasc Surg. 1980;79(3):338-48.

11. Sakata $Y$, Syed Z, Salinger MH, Feldman T. Percutaneous balloon aortic valvuloplasty: antegrade transseptal vs. conventional retrograde transarterial approach. Cathet Cardiovasc Interv. 2005;64(3):314-21.

12. Lieberman EB, Bashore TM, Hermiller JB, Wilson JS, Pieper KS, Keeler GP, Pierce CH, Kisslo KB, Harrison JK, Davidson CJ. Balloon aortic valvuloplasty in adults: failure of procedure to improve long-term survival. J Am Coll Cardiol. 1995;26(6):1522-8

13. Otto CM, Mickel MC, Kennedy JW, Alderman EL, Bashore TM, Block PC Brinker JA, Diver D, Ferguson J, Holmes DR Jr, et al. Three-year outcome after balloon aortic valvuloplasty. Insights into prognosis of valvular aortic stenosis. Circulation. 1994;89(2):642-50.

14. Alkhouli M, Zack CJ, Sarraf M, Bashir R, Nishimura RA, Eleid MF, Nkomo VT, Sandhu GS, Gulati R, Greason KL, et al. Morbidity and Mortality Associated With Balloon Aortic Valvuloplasty: A National Perspective. Circ Cardiovasc Interv. 2017;(5):10.

15. Galloway AC, Grossi EA, Baumann FG, LaMendola CL, Crooke GA, Harris LJ, Colvin SB, Spencer FC. Multiple valve operation for advanced valvular heart disease: results and risk factors in 513 patients. J Am Coll Cardiol. 1992:19(4):725-32

16. lung B, Baron G, Butchart EG, Delahaye F, Gohlke-Barwolf C, Levang OW, Tornos $\mathrm{P}$, Vanoverschelde $\mathrm{L}$, Vermeer $\mathrm{F}$, Boersma $\mathrm{E}$, et al. A prospective survey of patients with valvular heart disease in Europe: the euro heart survey on Valvular heart disease. Eur Heart J. 2003;24(13):1231-43.

17. Matsumura Y, Gillinov AM, Toyono M, Oe H, Yamano T, Takasaki K, Saraiva RM, Shiota T. Echocardiographic predictors for persistent functional mitral regurgitation after aortic valve replacement in patients with aortic valve stenosis. Am J Cardiol. 2010;106(5):701-6.

18. Unger $P$, Dedobbeleer $C$, Vanden Eynden F, Lancellotti $P$. Mitral regurgitation after transcatheter aortic valve replacement: does the prosthesis matter? Int J Cardiol. 2013;168(2):1706-9.

\section{Publisher's Note}

Springer Nature remains neutral with regard to jurisdictional claims in published maps and institutional affiliations.

Ready to submit your research? Choose BMC and benefit from:

- fast, convenient online submission

- thorough peer review by experienced researchers in your field

- rapid publication on acceptance

- support for research data, including large and complex data types

- gold Open Access which fosters wider collaboration and increased citations

- maximum visibility for your research: over $100 \mathrm{M}$ website views per year

At BMC, research is always in progress.

Learn more biomedcentral.com/submissions 